\title{
Refletindo sobre a tematização do futebol na Educação Física escolar
}

\author{
Osmar Moreira de Souza Júnior 12 \\ Suraya Cristina Darido 13 \\ ${ }^{2}$ Departamento de Educação Física e Motricidade Humana da UFSCar, São Carlos, \\ SP, Brasil \\ ${ }^{3}$ Instituto de Biociências. UNESP, Univ Estadual Paulista, Campus de Rio Claro, \\ Departamento de Educação Física, Rio Claro, SP, Brasil
}

\begin{abstract}
Resumo: A Educação Física deve propiciar ao aluno o exercício da cidadania, possibilitando a conquista da autonomia, por meio da reflexão-crítica sobre os conhecimentos da cultura corporal de movimento. Contudo, a área carece de subsídios para uma melhor organização de seus conteúdos dentro do currículo escolar. Neste sentido, o objetivo do presente estudo consiste em apontar um conjunto de temas relevantes do conteúdo futebol que possam servir de subsídios para propostas de sistematização para o componente curricular Educação Física escolar. São apresentados nove temas que discutem aspectos relevantes do futebol, tais como suas relações com a arte, sua história e o contexto do futebol feminino. Por fim, o tema relativo aos jogos da cultura popular relacionados ao futebol foi aprofundado por meio do futebol de tampinhas e do futebol de botão, incluindo aprendizagens como a construção de regras, a interpretação de competições e a valorização da cultura popular.
\end{abstract}

Palavras-chave: Educação Física escolar. Futebol. Conteúdos. Organização.

\section{Thinking about the football theme on school Physical Education}

\begin{abstract}
Physical Education should provide students the means to enable them the exercise of their citizenship, which will allow them to acquire autonomy through critical reflection on the knowledge of practicing body movement. Nevertheless, in the school curriculum the subject still lacks support in order to organize its contents. As such, the target of this study is to highlight a number of relevant issues on the contents of football practice, which may be used in an attempt to codify Physical Education as a school subject. Nine issues are here presented, which discuss relevant aspects of football, as well as its correlation with art, its history, and the female football background. Fin ally, we get into a deeper study of the games used in popular culture and its link to football, through games such as "button football", including learning processes such as rule system, the interpretation of competitions, and the appraisal of popular culture.
\end{abstract}

Key Words: Physical Education in school. Football. Contents. Organization.

\section{Introdução}

Consideramos que o ponto de partida para a construção de uma identidade da Educação Física escolar que contribua para sua valorização do ponto de vista educacional deva, necessariamente, passar pela compreensão do papel da escola em nossa sociedade.

Concordamos com González (2006) que entende que a escola tem entre suas funções a de introduzir os alunos no mundo sociocultural que a humanidade tem construído, com o objetivo de torná-los parte do projeto de (re) construção desse mundo.

Nesta perspectiva é necessário identificar de que forma a Educação Física poderia contribuir para a concretização deste projeto e, assim como

\footnotetext{
1 Pesquisadores do LETPEF - Laboratório de estudos e trabalhos pedagógicos em Educação Física, UNESP, Rio Claro, SP, Brasil
}

González (2006), temos trabalhado com a compreensão de que a educação física, tradicionalmente tem sido pensada dentro de um projeto educacional pautado pela idéia de leitura do mundo.

É preciso lembrar que a Educação Física passou mais recentemente, no meio acadêmico e no aspecto legal, a ser reconhecida como um componente curricular, incluindo-se assim, no rol das disciplinas escolares, tratando de um conjunto de conhecimentos que, organizados e sistematizados, contribui para a formação cultural do aluno.

A este conjunto de conhecimentos que a Educação Física compreende costumamos chamar, entre outras denominações, de cultura corporal de movimento. Dentro do universo de produções da cultura corporal, algumas práticas foram incorporadas pela Educação Física como 
objetos de ação e reflexão, como os jogos e as brincadeiras, os esportes, as danças, o conhecimento sobre o corpo, as ginásticas e as lutas, que têm em comum a representação corporal de diversos aspectos da cultura humana. São atividades que ressignificam a cultura corporal humana e o fazem utilizando ora uma intenção mais próxima do caráter lúdico, ora mais próxima do pragmatismo e da objetividade (BRASIL, 1998, p.29).

Portanto, o papel da Educação Física escolar, dentro de uma proposta que se encaminhe no sentido da formação de um aluno dotado das competências necessárias para uma leitura crítica do mundo em que vivemos, passa pela introdução deste aluno na esfera da cultura corporal de movimento.

Deste modo, possibilita-se o usufruto deste recorte da cultura geral, apropriando-se dela, reproduzindo-a, transformando-a, ressignificandoa, transmitindo-a, enfim, incorporando a cultura corporal de movimento de forma autônoma e significativa. Em outras palavras, poderíamos afirmar que a Educação Física permite aos alunos compreenderem manifestações como a ginástica, podendo praticá-la em ambientes não-escolares, incorporar elementos da ginástica em seu cotidiano, adaptando-os às suas necessidades $e$ vinculando-os aos sentidos que melhor atendam às suas necessidades.

Assim, entendemos que a Educação Física, juntamente com os demais componentes curriculares, deva propiciar ao aluno o exercício da cidadania, formando o aluno crítico, capaz de conquistar a autonomia, por meio do conhecimento, reflexão e transformação da cultura corporal de movimento.

Contudo, muitos professores de Educação Física mantêm-se ainda influenciados pela concepção esportivista e continuam restringindo as aulas aos esportes mais tradicionais, como, por exemplo, basquetebol, voleibol e futebol. Não bastasse este fato, é muito comum que estes conteúdos esportivos sejam transmitidos superficialmente, apenas na ótica do saber fazer, ou seja, na dimensão procedimental, o que acaba ocasionando a falta de aprofundamento dos conteúdos propostos para a Educação Física na escola.

Darido et al. (2008) consideram que alguns professores de Educação Física têm sistematizado os conteúdos na prática pedagógica a partir de suas próprias experiências em função, entre outros fatores, da carência de referenciais teóricos da área que forneçam subsídios para esta finalidade.

Consideramos que a identificação, seleção e organização de um conjunto de temas da cultura corporal de movimento é de fundamental importância para a construção de uma identidade da Educação Física escolar enquanto área responsável por um conjunto de conhecimentos.

No presente estudo nossa análise recairá sobre o futebol, fenômeno que apresenta inúmeros aspectos que possibilitam um tratamento didático-pedagógico. A apresentação destes aspectos na forma de temas propicia uma abordagem diversificada e aprofundada do futebol enquanto conteúdo, contemplando as dimensões procedimentais, atitudinais e conceituais.

Neste sentido, o objetivo do presente estudo consiste em apontar um conjunto de temas relevantes do conteúdo futebol que possam servir de subsídios para propostas de sistematização para o componente curricular Educação Física escolar.

\section{Metodologia}

Do ponto de vista da forma de abordagem do problema a ser pesquisado, este estudo baseiase em uma pesquisa do tipo qualitativa. A pesquisa qualitativa consiste na metodologia adotada pelas ciências sociais, que sustenta que os fenômenos humanos e sociais são muito complexos e dinâmicos, o que torna quase impossível o estabelecimento de leis gerais como na física ou na biologia. O objetivo desta metodologia de pesquisa consiste no entendimento de um fato particular ao invés da sua explicação causal. Além disso, o contexto particular em que ocorre o fato é um elemento essencial para a sua compreensão (ANDRÉ; OLIVEIRA, 1995).

Do ponto de vista dos procedimentos técnicos, o presente estudo estará baseado em um referencial de pesquisa bibliográfica. De acordo com Gil (apud SILVA; MENEZES, 2001) a pesquisa bibliográfica consiste em um tipo de pesquisa desenvolvida a partir de materiais já publicados, constituídos principalmente de livros, artigos de periódicos e textos disponíveis na internet.

Embora quase todo trabalho científico 
compreenda algum tipo de investigação desta natureza, a pesquisa bibliográfica possui a especificidade de ter este método como ferramenta exclusiva para a coleta dos dados. A principal vantagem da pesquisa bibliográfica reside no fato deste formato de pesquisa contemplar um universo de conhecimentos muito mais amplo em relação ao que se poderia investigar de forma direta.

\section{Diversificação e aprofundamento dos conteúdos}

Segundo Coll (2000) há uma reivindicação freqüente de que na escola sejam ensinados e aprendidos outros conhecimentos considerados tão ou mais importantes do que fatos e conceitos.

O autor afirma que além destes fatos e conceitos espera-se que sejam ensinadas estratégias ou habilidades para resolver problemas, selecionar a informação pertinente em uma determinada situação ou utilizar os conhecimentos disponíveis para enfrentar situações novas ou inesperadas, por exemplo. Espera-se ainda que os alunos aprendam a trabalhar em equipe, a serem solidários com os colegas, a respeitar e valorizar o trabalho dos outros ou não discriminar as pessoas por motivos de gênero, idade ou outro tipo de características individuais.

Contudo, de acordo com Darido e Souza Júnior (2007), a Educação Física, ao longo de sua história, priorizou os conteúdos numa dimensão quase que exclusivamente procedimental, o saber fazer e não o saber sobre a cultura corporal de movimento ou como se deve ser, embora esta última categoria aparecesse na forma do currículo oculto ${ }^{2}$.

Outra crítica presente no discurso de alguns autores diz respeito ao fato da Educação Física estar vinculada apenas a uma parcela da cultura corporal de movimento, representada mais especificamente pelos esportes coletivos, especialmente aqueles mais praticados no Brasil como futebol, voleibol e basquetebol. Discutindo este tema Rangel-Betti (1995) questiona a contradição entre os currículos das faculdades

\footnotetext{
${ }^{2}$ O currículo oculto corresponde àquele tipo de conhecimento não-sistematizado que permeia os currículos escolares, mas não se configura como objeto de tratamento didáticopedagógico pelos atores do processo de ensino $e$ aprendizagem, como, por exemplo, as estratégias adotadas para a divisão de equipes, que podem favorecer a inclusão ou promover situações de exclusão e/ou humilhação de alguns alunos.
}

que formam os docentes de Educação Física que compreendem disciplinas como dança, capoeira, judô, atividades expressivas, ginástica, folclore entre outras e a prática pedagógica destes professores que, em geral, restringe-se ao ensino dos esportes coletivos "tradicionais".

Segundo Kunz (1994) o esporte como conteúdo hegemônico impede o desenvolvimento de objetivos mais amplos para a Educação Física, tais como o sentido expressivo, criativo e comunicativo.

Para facilitar a adesão dos alunos às práticas corporais seria importante diversificar as vivências experimentadas nas aulas, para além dos esportes tradicionais (futebol, voleibol ou basquetebol). $\mathrm{Na}$ verdade, a inclusão e a possibilidade das vivências das ginásticas, dos jogos, das brincadeiras, das lutas, das danças podem facilitar a adesão do aluno à medida que aumentam as chances de uma possível identificação.

É importante ressaltar também que a Educação Física na escola deve incluir tanto quanto possível todos os alunos nos conteúdos que propõe. Não se pode mais tolerar a exclusão que historicamente tem caracterizado a Educação Física na escola. Todos os alunos têm direito a ter acesso ao conhecimento produzido pela cultura corporal de movimento.

Portanto, a diversificação dos conteúdos representa um dos primeiros aspectos a serem considerados para uma Educação Física renovadora em uma perspectiva inclusiva. Contudo, é necessário reconhecer ainda que o papel da Educação Física ultrapassa o ensinar esporte, ginástica, dança, jogos, atividades rítmicas, expressivas e conhecimento sobre o próprio corpo para todos, em seus fundamentos e técnicas (dimensão procedimental), mas inclui também os seus valores subjacentes, ou seja, quais atitudes os alunos devem ter nas e para as atividades corporais (dimensão atitudinal). E, finalmente, busca garantir o direito do aluno de saber porque ele está realizando este ou aquele movimento, isto é, quais conceitos estão ligados àqueles procedimentos (dimensão conceitual).

Para garantir um ensino de qualidade além de diversificar os conteúdos na escola é preciso aprofundar os conhecimentos, ou seja, tratá-los nas três dimensões abordando os diferentes aspectos que compõem as suas significações. Ou 
seja, quando for tratar o futebol, ir além do fazer (técnicas e táticas), mas abordar a sua presença na cultura, as suas transformações ao longo da história, a dificuldade da expansão do futebol feminino (causas e efeitos), a mitificação dos atletas de futebol, os grandes nomes do passado, a violência nos campos de futebol, entre outras possibilidades. Ou seja, é preciso ir além do costumeiro jogar (DARIDO; SOUZA JÚNIOR, 2007).

Um ponto de destaque nessa nova significação atribuída à Educação Física é que a área ultrapassa a idéia única de estar voltada apenas para o ensino do gesto motor correto. Muito mais que isso, cabe ao professor de Educação Física problematizar, interpretar, relacionar, compreender com seus alunos as amplas manifestações da cultura corporal de movimento, de tal forma que os alunos compreendam os sentidos e significados impregnados nas práticas corporais.

\section{Sistematização de conteúdos e materiais didáticos como possibilidades de avanço para a Educação Física na escola}

De acordo com González (2006), um projeto curricular consiste na explicitação dos saberes considerados fundamentais em nossa área de conhecimento, sistematizados em uma seqüência que, supostamente, facilitaria 0 processo de assimilação ativa e criativa.

O autor acrescenta ainda que seria impossível a criação de um modelo de projeto curricular na área para toda e qualquer escola, professor e aluno. Por outro lado, considera que seja perfeitamente viável a identificação de um conjunto de princípios orientadores gerais.

Partir destes princípios orientadores gerais seria, por exemplo, assumir uma visão macroestrutural de currículo, que pressupõe que o planejamento de uma determinada série deve ser elaborado apenas após a construção de um perfil daquilo que o aluno deverá vivenciar em termos de Educação Física ao longo da Educação Básica

Orientar os currículos a partir destes princípios gerais permite a construção de propostas curriculares que atendam às necessidades específicas de diferentes contextos educacionais.

Atualmente foram publicados alguns estudos preocupados em discutir a sistematização dos conteúdos na Educação Física, como por exemplo, Freire e Scaglia (2003), Rosário e Darido (2005), Rosário (2006), González (2006), Kravchychyn, Oliveira e Cardoso (2008), para citar alguns.

Estes estudos têm linhas de investigação bastante diferentes. Rosário e Darido (2005) buscaram levantar informações sobre como os professores de Educação Física experientes pensam e/ou realizam 0 processo de sistematização dos conteúdos. Em outras palavras, buscaram extrair da experiência docente informações/conhecimentos sobre a sistematização dos conteúdos.

González (2006) e Kravchychyn, Oliveira e Cardoso (2008) buscaram compreender as implicações da implementação e avaliação de uma proposta de sistematização para a Educação Física escolar. Já Freire e Scaglia (2003) elencam propostas de sistematização e Rosário (2006) buscou identificar alguns princípios para a sistematização de conteúdos a partir da análise dos livros didáticos das disciplinas de História e Ciências.

Kunz (1994) entende que a elaboração de um programa mínimo poderia resolver a "bagunça" interna da disciplina, um programa de conteúdos baseados na complexidade e com objetivos definidos para cada série de ensino. Esse programa traria opções para o professor que implementa um mesmo conteúdo, com a mesma complexidade, tanto para a $5^{\text {a }}$ série do Ensino Fundamental quanto para o Ensino Médio.

É preciso deixar claro que a sistematização dos conteúdos é apenas um aspecto, que deve ser discutido academicamente, e que certamente existem muitos outros problemas e questões a serem investigadas no interior da Educação Física escolar. O ponto crucial, anterior à questão da sistematização, é definir o que é absolutamente necessário ensinar nas aulas de Educação Física.

Acreditamos que não seja possível termos um currículo único de Educação Física para todas as escolas brasileiras, pois as diferenças entre os alunos, espaços, vivências, contextos, não permitem a construção de uma proposta consensual.

Uma possibilidade de sistematização dos conteúdos da Educação Física pode ser encontrada ainda, na elaboração de materiais 
didáticos que sirvam de apoio para a prática docente.

Os materiais didáticos ou materiais curriculares são instrumentos que proporcionam ao professor critérios e referências para tomar decisões, tanto na intervenção direta do processo de ensino e aprendizagem, quanto no planejamento e na avaliação. Assim, constituemse nos meios que auxiliam os docentes na resolução dos problemas que as diferentes fases do planejamento, implementação e avaliação apresentam.

Os livros didáticos podem ser considerados hoje como a estratégia metodológica mais utilizada pelos professores, chegando muitas vezes, de acordo com Zabala (1998), a ditar as atividades dos mesmos. Apesar desta constatação, estes materiais constantemente são criticados e até menosprezados, por uma série de fatores.

Apesar do reconhecimento de que as críticas ao livro didático possuem fundamentos procedentes, concordamos com Zabala (1998) que afirma ser possível construir materiais didáticos que não cometam os erros dos livros didáticos convencionais, superando o referencial estritamente transmissor, atribuído a este tipo de recurso.

Aliás, o termo recurso deve pautar as reflexões acerca do papel do livro didático, tendo em vista que, conforme aponta Munakata (2003), o livro didático não é um portal que se abre para que o leitor possa colher idéias perfeitas ou ideologias, e sim um objeto educacional a ser manipulado pelo professor e os alunos.

É necessário compreender que a complexidade do processo educativo exige que 0 professor disponha de recursos e instrumentos que o auxiliem na tarefa de ensinar. Neste sentido, cabe evidenciar a necessidade de materiais que possam estar disponíveis para respaldar as propostas didáticas do professor, incentivando sua criatividade e a diversificação de estratégias, e não o contrário.

O material didático pode auxiliar os professores na prática pedagógica, pois serve como referencial e pode ser transformado pelo docente de acordo com a realidade na qual atua e as necessidades dos alunos.

\section{Apresentação de temas do futebol para a Educação Física escolar}

O futebol é o conteúdo que está mais presente nas aulas de Educação Física em nosso país, contudo, o futebol "ensinado" nestas aulas raramente ultrapassa os aspectos técnicos e o jogar livremente.

Cabe, portanto, questionarmos quais seriam os aspectos referentes ao futebol que mereceriam receber um tratamento didático-pedagógico no sentido de contribuir para a proposta de formação de alunos críticos e autônomos na tarefa de ler e interpretar o mundo à sua volta.

A identificação, seleção e organização destes aspectos certamente poderia ser uma tarefa levada a cabo pelo próprio professor, entretanto, não podemos negar que quanto mais ferramentas ele tiver à sua disposição, menos desgastante e mais diversificada e aprofundada se tornará esta ação.

A proposta de tematização do futebol apresentada neste estudo baseia-se num livro ainda em fase de editoração - construído com o intuito de contribuir para as reflexões relacionadas à prática pedagógica em Educação Física escolar e também do livro já publicado por Darido, Souza Júnior (2007).

Foram selecionados e desenvolvidos temas sobre os conteúdos da cultura corporal de movimento considerados importantes de serem tratados nas aulas de Educação Física, além de elaborar e sugerir estratégias para o desenvolvimento de temas.

Os temas de cada conteúdo foram estruturados basicamente com sugestões de rodas, pesquisas, leituras, sessão de memórias, curiosidades, vivências e discussões, colocados em ordens diversas, de acordo com as necessidades de abordagem.

As sugestões oferecidas no livro pretendem a apropriação por parte dos alunos de conceitos, procedimentos e atitudes, relativos aos diversos temas, devendo ocorrer de forma integrada. Lembramos que pesquisar, ler, vivenciar e discutir são maneiras de adquirir conhecimentos e tornar as aprendizagens mais significativas.

O conteúdo futebol foi estruturado em nove temas que consideramos significativos e passíveis de tratamento didático pedagógico. Por meio de cada um destes nove temas foi possível 
diversificar e aprofundar o conteúdo futebol relacionando-o aos conhecimentos de outras áreas, além do que, cabe ressaltar como já dissemos anteriormente, que a adoção de diferentes estratégias didáticas para o tratamento dos conteúdos proporciona a aprendizagem significativa destes conhecimentos.

Para melhor ilustrar estas possibilidades, optamos por uma apresentação, em linhas gerais, das possibilidades de aprendizagens proporcionadas por cada um dos temas de futebol.

- Dimensões sociais do esporte: educação, participação e rendimento - a proposta desenvolvida neste tema consiste em fazer com que os alunos reflitam sobre as diferenças encontradas nas formas de se praticar esporte. Por meio de textos, discussões e vivências é possível identificar os significados particulares que estão presentes quando se joga um "rachão" no clube, quando se assiste a um jogo do campeonato brasileiro e quando se joga futebol na escola, objetivando a inclusão de todos independente do nível de habilidade. $O$ jogo de futebol de casais ou de pares é a vivência que fornece um pano de fundo para estas discussões e re-significações do esporte escolar.

- A origem do futebol: do jogo ao esporteeste tema pretende apresentar um pouco da evolução histórica do futebol, apontando fatos que comprovam a forma como um conjunto de jogos com os pés e até com as mãos, espalhados pelo mundo convergiram para a institucionalização do esporte futebol que conhecemos hoje. Dentre as vivências indicadas para este fim, cabe destacar a produção de textos denominada de "reinventando a histórica do futebol", por meio da qual os alunos em grupos criam histórias fictícias para a origem do esporte. Tal estratégia proporciona a criação em grupo, o diálogo, a cooperação, a reflexãocrítica, entre outras habilidades e competências que se juntam para a resolução de um problema tematizado pelo futebol.

- Futebol e cultura popular: o esporte volta a ser jogo - neste tema os jogos da cultura popular como rebatida, gol-de-cabeça e jogo de golzinhos são resgatados no espaço escolar, para ilustrar a forma como o esporte institucionalizado, criado a partir de jogos, se desmembra em outros jogos que são praticados de diferentes maneiras pelo mundo afora. $O$ resgate e valorização de jogos e brincadeiras de outras gerações também é um aspecto enfatizado por meio do encaminhamento de uma pesquisa com pessoas mais velhas.
- Futebol no Brasil: da elite ao povo - com este tema os alunos tomam conhecimento da origem elitista do futebol brasileiro, que excluía os pobres e principalmente negros e mulatos, cabendo uma discussão e reflexão sobre a apropriação do futebol pela população de baixa renda que tem nesse esporte além de opção de lazer a expectativa de ascensão socioeconômica. A vivência de um jogo de futebol no qual o critério da escolha das equipes e o tempo de jogo excluam da aula os alunos menos habilidosos serve de pano de fundo para uma discussão sobre a forma como o esporte escolar pode ser excludente e cruel para quem não possui determinado "nível de habilidade". O tema compreende ainda uma galeria de craques da história do futebol brasileiro e suas biografias, com o intuito de valorização da memória do futebol.

- Futebol e arte - as interfaces entre o futebol e as manifestações artísticas como a música, a pintura, a literatura e o cinema são tratados neste tema, que compreende a apreciação artística e a produção de obras de arte que contextualizem o universo do futebol. Dentre as produções artísticas apresentadas no tema podemos destacar músicas como "Um a zero" de Pixinguinha, "Time perna de pau" dos Demônios da garoa" e "É uma partida de futebol" do Skank, na pintura a obra "Futebol" pintada em 1935 por Cândido Portinari é o motivo para uma apreciação crítica e releitura, na literatura apresentamos crônicas como "Barbosa o injustiçado" de Eduardo Galeano e "Pelé eterno me trouxe a infância de volta" de Arnaldo Jabor, além da poesia "O anjo de pernas tortas" de Vinícius de Moraes, aliás o Filme " Garrincha - a estrela solitária" aparece como a indicação de filme. A apreciação e releitura destas obras de arte permitem ainda projetos interdisciplinares com os professores de artes e literatura, por exemplo.

- Fundamentos técnicos do futebol - a abordagem do tema relacionado à técnica é introduzida com um texto da aprendizagem motora que justifica a necessidade de repetição de movimentos para a automatização dos gestos motores, necessária no esporte de rendimento. No desenvolvimento do tema os alunos tomam contato com exercícios específicos para o treinamento dos fundamentos técnicos do futebol e como um contraponto são sugeridas as exibições de dois filmes, o curta-metragem "Uma história de futebol" e o longa "Pelé eterno", que possibilitam a reflexão sobre o talento esportivo, o treinamento e a valorização das diferentes competências e habilidades em prol da coletividade em uma equipe de futebol.

- Futebol e ética - este tema é apresentado por meio de questões que façam os alunos refletirem sobre atitudes como honestidade, justiça e solidariedade no futebol, em seguida eles participam de uma vivência de jogos de futebol 
propositalmente pautado por regras injustas que acabam por excluir ou menosprezar uma parcela dos alunos. Para se fazer o contraponto, em outra vivência os alunos participam de jogos de futebol em equipes equilibradas e com critérios justos de disputa, em seguida é encaminhada uma discussão sobre as questões éticas envolvidas em cada uma das vivências. Este tema compreende ainda a leitura do texto "A máfia do apito" (Revista Veja, setembro de 2005) que provoca reflexões e discussões sobre a ética no futebol, por meio de um episódio da manipulação de resultados pela arbitragem brasileira, bastante repercutido na imprensa no ano de 2005.

- Futebol feminino e o seu contexto - a partir de uma vivência em que os alunos têm a oportunidade de jogar futebol em grupos mistos e posteriormente separados por sexo, é encaminhada uma discussão no sentido de refletir sobre a construção diferenciada dos corpos masculinos e femininos em nossa sociedade que repercute, entre outros aspectos, nas diferenças motoras entre os gêneros. O tema apresenta ainda textos que discutem a história do futebol feminino em nosso país e o preconceito enfrentado pelas meninas que "se arriscam" a jogar futebol no Brasil. Por fim, a partir de um texto que narra o caso da menina Mariana que foi impedia de participar das competições de futebol no Estado de Santa Catarina, é proposto um júri simulado com a turma que discute e reflete sobre a temática do futebol feminino e do preconceito de gênero.

Para ilustrarmos de forma ainda mais precisa as estratégias de ensino adotadas para a contextualização dos temas, iremos apresentar o tema "Resgate de jogos da cultura popular" de uma forma mais detalhada, omitindo apenas alguns dos textos em função do espaço disponível.

- Resgate de jogos da cultura popular: Roda inicial - neste tema será apresentada uma proposta de resgate de jogos da cultura popular que têm como fonte inspiradora o futebol - o futebol de dedos ou futebol de tampinhas e o futebol de botão - e que possibilita a exploração de temas como a construção de regras e a compreensão da lógica da organização de torneios e campeonatos esportivos.

A explanação do tema inicia-se com 0 questionamento aos alunos sobre os conhecimentos que possuem em relação a torneios ou campeonatos esportivos, incluindo sistemas de disputa, contagem de pontos, sistemas de classificação etc.

\section{Pesquisa}

$A$ atividade pode ter início algumas aulas antes da implementação propriamente dita, através da proposição de uma pesquisa com os pais, familiares, vizinhos ou amigos mais velhos que pode ser desenvolvida da seguinte maneira: cada aluno ou cada grupo de 3 ou 4 alunos deve entrevistar uma pessoa com mais de 30 anos de idade que já tenha brincado do jogo das tampinhas ou do futebol de botão. A idéia da pesquisa é fazer um levantamento de como eram as regras destes jogos há algum tempo atrás e buscar resgatá-las.

Em seguida, pedir para que os alunos apresentem 0 resultado das pesquisas, finalizando esta atividade com um debate com a turma para que sejam construídos a partir destes resultados e das leituras e discussões anteriores, manuais com as regras do jogo das tampinhas e de futebol de botão da turma ou da escola.

\section{Leitura: "Resgate de jogos e brincadeiras: 0 jogo de futebol de tampinhas}

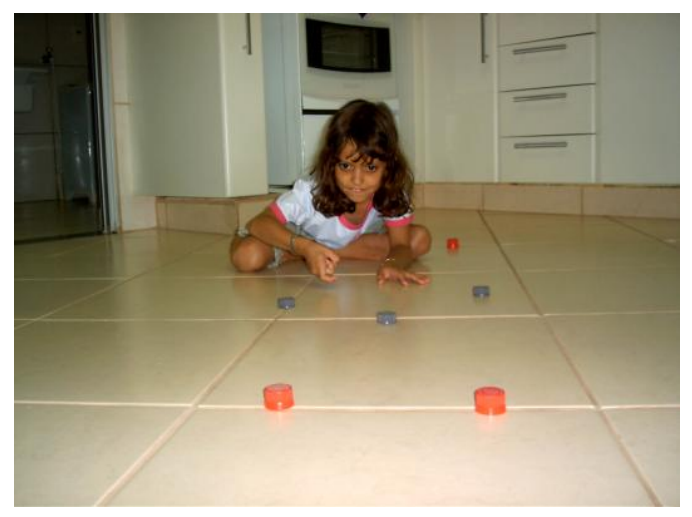

Figura1. Menina joga futebol de tampinhas.

Vamos conhecer um jogo que em muitos lugares já está desaparecido, mas foi muito praticado por outras gerações, esse jogo pode receber diferentes nomes dependendo da região, mas vamos chamá-lo aqui de "futebol de tampinhas". A idéia de resgatar o futebol de tampinhas é, em primeiro lugar não deixar que essa brincadeira caia no esquecimento, pois uma das formas de perpetuação das brincadeiras populares sempre foi a transmissão oral, e o outro motivo é porque esse é um jogo bastante divertido e que não exige nenhum tipo de material sofisticado, bastam 3 tampinhas de garrafas pet ou até pedrinhas.

O jogo é feito para dois jogadores, que atacam com as mesmas tampinhas. Para iniciar o jogo, um dos jogadores posiciona as 3 tampinhas próximo ao seu gol formando um triângulo. As tampinhas devem ser deslocadas com toquinhos 
com a lateral do dedo dobrado, com "petelecos" ou ainda com a lateral da palma da mão, desde que não sejam conduzidas. As tampinhas devem ser tocadas de forma que sempre a que foi empurrada passe pelo meio das outras duas, ou seja, formando uma espécie de trança.

Para que as nossas regras fiquem mais claras, podemos fixar um número de toques, que será de 4, ou seja, o jogador cruza 1, 2, 3 vezes e no quarto cruzamento deve finalizar ao gol. Se durante o ataque alguma das tampinhas sair do campo pela lateral ou pela linha de fundo ou a tampinha lançada não passar pelo meio das outras duas, o jogador perde 0 ataque e 0 adversário inicia o seu ataque colocando as 3 tampinhas em formato de triângulo, na frente de seu gol. Se a tampinha virar de lado e sair rolando, mas não sair do campo, é só esperá-la parar e deitá-la novamente para continuar a jogada.

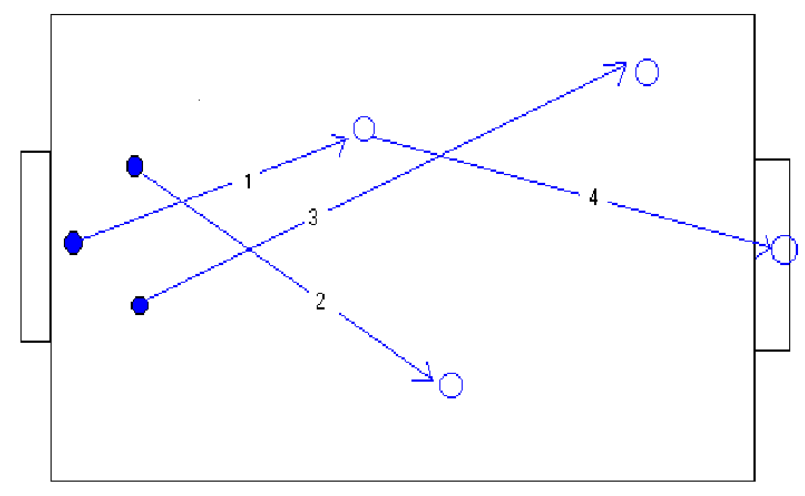

Figura 2. Representação da movimentação das tampinhas.

Cada jogador tem direito a 5 ataques, que são feitos de forma alternada, ou seja, jogador $A$ ataca primeiro, em seguida ataca o jogador $B$, depois novamente o $A$, e assim sucessivamente até que ambos tenham atacado 5 vezes. Se o jogo for de um campeonato onde não puder haver empates e depois de 5 jogadas terminar empatado, cada jogador irá fazer uma jogada até que alguém desempate o jogo.

Estão aí as regras do futebol de tampinhas, mas se vocês optaram por jogar com regras diferentes não tem problema nenhum, o importante é que vocês adotem um código de regras e o respeitem.

\section{Leitura: Conhecendo o futebol de botão}

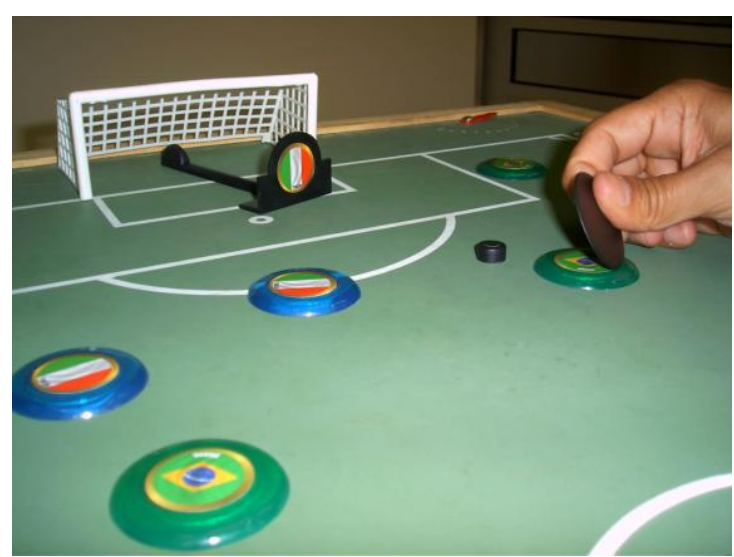

Figura 3. Jogo de futebol de botão.

O futebol de botão pode ser pensado como um jogo de futebol de "tabuleiro" ou de mesa. Neste jogo duas pessoas se enfrentam, ficando cada uma delas com um time composto por 10 botões que representam os jogadores de linha e uma peça que representa o goleiro.

Cada jogador (praticante) tem a sua vez de jogar, ou seja, eles não movimentam seus botões ao mesmo tempo, enquanto um jogador está fazendo sua jogada o adversário fica assistindo e esperando a sua vez de jogar, que pode ser depois de um determinado número de toques do adversário (dependerá da regra escolhida ou estabelecida), depois que ele errar a bolinha ou depois que ele fizer uma falta (quando o botão que a pessoa movimentou choca-se com um botão do adversário).

O futebol de botão não possui um conjunto de regras oficiais padronizado de forma 'universal', aliás é importante notarmos que as regras do jogo podem variar muito de região para região. O princípio básico da dinâmica do futebol de botão, consiste em pressionar o botão com uma palheta e fazê-lo tocar na bolinha (que pode ser de formato arredondado mesmo, de pastilha ou de dado), mas o número de toques permitido, as infrações para os choques entre os botões, o "chute" a gol, a organização e distribuição dos jogadores pelo campo durante o jogo etc., variam de regra para regra ${ }^{3}$.

\footnotetext{
${ }^{3}$ Através da Resolução N.- 14, de 29 de setembro de 1988,

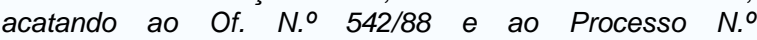
23005.000885/87-18, baseado na Lei N.o 6.251, de 8 de outubro de 1975 e no Decreto N.9 80.228, de 25 de agosto de 1977, assinada pelo seu então ConselheiroPresidente Manoel José Gomes Tubino, o CND (Conselho Nacional de Desportos) reconhece o Futebol de Mesa como modalidade desportiva praticada no Brasil, como uma vertente dos esportes de salão, no qual se incluem o xadrez e o bilhar, por exemplo. O Futebol de Mesa é praticado
} 


\section{Faça você mesmo}

Uma dica interessante para tornar os jogos de futebol de botão ainda mais interessantes é personalizar os próprios times. Para isso os alunos podem tanto utilizar escudos de times de sua preferência como fotos dos jogadores. Deste modo eles poderão montar os seus times do coração com os craques que estão atuando no momento ou escolher as suas seleções com os craques que preferirem em todos os tempos.

\section{Discussão}

Discuta com a turma a importância do resgate e preservação dos jogos da cultura popular por meio de questões como "O que vocês acharam de conhecer o futebol de tampinhas e o futebol de botão?"; "Por que vocês acham que jogos da cultura popular como o futebol de tampinhas e de botão não são conhecidos das pessoas hoje em dia?"; "O que podemos fazer para preservar e resgatar jogos como o futebol de tampinhas e de botão?"; "Vocês conhecem algum jogo que considerem que corra risco de ser esquecido no futuro? Quais e por quê?", entre outras possíveis.

\section{Leitura: Entendendo os campeonatos e torneios esportivos}

Todos nós acompanhamos de alguma maneira as competições esportivas que acontecem em nosso país e no exterior. Alguns mais fanáticos acompanham campeonatos brasileiros, espanhol, italiano, alemão, inglês de futebol, NBA (Liga profissional norte-americana de basquetebol), campeonatos de voleibol, etc. Outros menos fanáticos entram no clima de torcedores apenas de 4 em 4 anos durante a Copa do Mundo de Futebol e aí acabam tentando entender como funciona aquela competição.

Será que essas competições são todas iguais? Por que será que algumas se chamam campeonatos, outras torneios, outras copas e outras ainda ligas? Vamos tentar entender um pouquinho sobre como são organizadas estas competições.

Bem, primeiramente podemos distinguir duas formas básicas de competições esportivas que são os campeonatos e os torneios. Parece a mesma coisa, mas não é. Os campeonatos são

oficialmente em cinco modalidades; três oficiais (Disco, Bola 12 Toques, Bola 3 Toques) e duas experimentais (Dadinho $9 \times 3$ e Pastilha). http://pt.wikipedia.org/wiki/Futebol de bot\%C3\%A3o Acesso em 09/06/2010. aquelas competições nas quais todos os participantes se enfrentam como acontece no Brasileirão de futebol e os torneios são competições onde geralmente as equipes são divididas em grupos, jogando apenas com as equipes do próprio grupo, classificando-se as melhores equipes para as próximas fases até chegarmos em duas equipes finalistas que decidem para saber quem será o campeão, como é a Copa do Mundo, por exemplo.

Para facilitar, vamos tentar entender como isso funciona no futebol.

No Campeonato Brasileiro são 20 equipes que se enfrentam em turno e returno, ou seja todos jogam contra todos duas vezes, uma em seu estádio como mandante do jogo e outra no estádio do adversário como visitante. Por exemplo, o Cruzeiro joga duas vezes contra o Flamengo, no campeonato, uma no Maracanã como visitante e outra no Mineirão como mandante. Portanto, no Brasileirão, todos os times irão jogar 19 vezes em casa e 19 vezes fora de casa, totalizando 38 jogos.

Mas como saber quem está em $1^{\circ}$ lugar, em $2^{\circ}$, em $3^{\circ}$ e assim por diante?

Bem, os campeonatos como o Brasileirão são chamados também de campeonatos de pontos corridos, sendo assim, os times pontuam a cada jogo e a soma destes pontos define a classificação. No caso específico do futebol, os times que vencem os jogos somam 3 pontos por partida, independente do placar do jogo, no caso de empate, cada time soma 1 ponto na classificação e o time que é derrotado não ganha nenhum ponto. Ao final do campeonato o time que conseguir somar o maior número de pontos é declarado campeão. Caso dois ou mais times somem o mesmo número de pontos existem os critérios de desempate que definem qual equipe fica classificada à frente da outra. No regulamento do Brasileirão, fica estabelecido também o sistema de acesso e rebaixamento (os 4 últimos colocados na classificação final são rebaixados para a série $B$ e os 4 primeiros da série $B$ são promovidos para a série $A$, no ano seguinte).

No caso dos torneios como a Copa do Mundo ou a Taça Libertadores da América, por exemplo, as equipes são divididas em grupos ou chaves, jogando apenas contra as equipes de sua própria chave na $1^{\underline{a}}$ fase e classificando-se para as próximas fases, um número de equipes limitado, 
determinado pelo regulamento de cada torneio. Nas fases subseqüentes o torneio pode assumir o formato de eliminatória simples, também chamado de mata-mata, no qual a equipe perdedora do confronto é eliminada da competição.

Os torneios de futebol, assim como os campeonatos seguem um sistema de classificação onde se atribuem 3 pontos para os vencedores 1 em caso de empate e nenhum para a derrota, estabelecendo também seus critérios de desempate para o caso de igualdade de pontos entre duas ou mais equipes, porém nas fases de eliminatória simples, como as oitavas, quartas ou semi-finais, em geral os jogos são decididos através de prorrogação (tempo extra após o jogo para que haja um desempate) e/ou disputa de pênaltis nos casos de empate. Em outros esportes como o basquetebol, o voleibol ou o handebol os sistemas de disputa também são similares, variando a contagem de pontos que depende das regras e regulamentos de cada modalidade.

\section{Vivência}

Organize com a turma um torneio de futebol de tampinhas e/ou de futebol de botão, onde eles serão os competidores e organizadores do torneio ao mesmo tempo. Inicialmente oriente os alunos para que eles sejam distribuídos em 8 grupos (caso a turma tenha 36 alunos por exemplo, teríamos 4 grupos com 4 integrantes e 4 grupos com 5), pois deste modo podemos seguir 0 mesmo sistema de disputas da Copa do Mundo, com oitavas, quartas, semi-finais e finais. $O$ próximo passo seria explicar para a turma que os grupos teriam que ser responsáveis pela organização e controle das respectivas tabelas e classificações, sendo que após a segunda fase os alunos eliminados passariam a ser os organizadores e árbitros dos jogos. O último passo seria o desenvolvimento do torneio em si, sendo que se possível ofereça algum tipo de premiação para os 3 primeiros colocados para colocar uma motivação extra.

Após o torneio faça com a turma uma avaliação de todo o processo para que os alunos reflitam sobre todos os conhecimentos que vivenciaram naquelas aulas como o resgate do jogo, os conhecimentos sobre a organização de torneios e campeonatos, a construção de regras e a vivência de tudo isso na prática.

\section{Considerações finais}

A construção de um projeto curricular guia, como proposto por González (2006), ou de outras propostas de sistematização dos conteúdos para a Educação Física escolar são ações fundamentais para que a disciplina se consolide enquanto componente curricular.

No presente estudo não tivemos a intenção de elaborar uma proposta de sistematização de conteúdos, mas sim de justificar a importância de um tratamento organizado dos conteúdos da Educação Física escolar, que pode ser colocado em prática tanto por meio de uma proposta de sistematização ou organização curricular, como por meio de materiais didáticos.

Além de buscar argumentos que justifiquem a importância destas estratégias de organização, o estudo demonstrou, por meio da tematização do futebol, como a identificação, seleção e organização de temas possibilita $\circ$ tratamento diversificado e aprofundado deste conteúdo.

Foram apresentados nove temas $e$ aprofundado apenas um deles neste estudo, contudo, é possível observar a riqueza de conhecimentos que são revelados por meio dos textos, vivências, pesquisas e outras estratégias de ensino adotadas para o tratamento didático pedagógico do tema "resgate de jogos populares".

Além de permitir a diversificação e o aprofundamento dos conteúdos e estratégias de ensino, a tematização vincula a Educação Física ao ensino e aprendizagem de conhecimentos, ultrapassando a dimensão exclusivamente procedimental tradicional na área e ampliando sua área de alcance para as dimensões conceitual e atitudinal.

\section{Referências}

ANDRÉ, M. A. E. D.; OLIVEIRA, M. S. N. R. (Coords). Etnografia da prática escolar. Campinas: Papirus, 1995.

BRASIL, Ministério da Educação e do Desporto. Parâmetros Curriculares Nacionais: Educação Física, Terceiro e Quarto Ciclos / Secretaria de Educação Fundamental. Brasília: MEC/SEF, 1998.

COLL, C. Os Conteúdos na Reforma: ensino e aprendizagem de conceitos, procedimentos e atitudes. Porto Alegre: Artmed, 2000.

DARIDO, S. C.; SOUZA JÚNIOR, O. M. Para ensinar educação física: possibilidades de 
intervenção na escola. Campinas: Papirus, 2007.

DARIDO, S. C.; CARVALHO, A. O.; BONFÁ, A. C.; BARROSO, A.; BARROS, A. M.;

FERNANDES, A.; RICCI, C. S.; IMPOLCETTO, F. M.; JESUS, G. B.; RODRIGUES, H.; TERRA, J.; FRANCO, L.; LADEIRA, M. F. T.; SERVILHA, N.; LOPES, O. P.; SOUZA JÚNIOR, O. M.; COLPAS, R. D.; GABRIEL, R. Z.; OLIVEIRA, R. S.;

GASPARI, T. A construção de um livro didático na Educação Física escolar: discussão, apresentação e análise. In: Pró-Reitoria de Graduação; PINHO, S. Z.; SAGLIETTI, J. R. C. Núcleos de ensino da Unesp - Edição 2008. São Paulo: Cultura Acadêmica Editora, 2008.

FREIRE, J. B.; SCAGLIA, A. J. Educação como Prática corporal. São Paulo: Scipione, 2003. (Pensamento e Ação no Magistério).

GONZÁLEZ, F. J. Projeto curricular e educação física: o esporte como conteúdo escolar. In: REZER, R. (org.) O fenômeno esportivo: ensaios crítico-reflexivos. Chapecó: Argos, 2006.

KRAVCHYCHYN, C.; OLIVEIRA, A. A. B.; CARDOSO, S. M. V. Implantação de uma proposta de sistematização e desenvolvimento da Educação Física no Ensino Médio. Movimento. Porto Alegre, v. 14, n. 02, p. 39-62, maio/agosto de 2008. Disponível em:

$<$ http://www.seer.ufrgs.br/index.php/Movimento/art icle/view/5753/3356>. Acesso em 05 de fev. 2009.

\section{KUNZ, E. Transformação didático-pedagógica} do esporte. ljuí: Unijuí, 1994.

MUNAKATA, K. Investigações acerca dos livros escolares no Brasil: das idéias à materialidade. In: VI Congresso Iberoamericano de História de la Educación Latinoamericana. San Luis Potosí. Anais do VI Congresso lberoamericano de História de la Educación Latinoamericana, ISBN 998-7727-87-X, 2003.

NEGRINE, A. Instrumentos de coleta de informações na pesquisa qualitativa. In: MOLINA NETO, V.; TRIVINÕS, A. N. S (Orgs). A pesquisa qualitativa na Educação Física: alternativas metodológicas. Porto Alegre: Editora Universidade UFRGS, 1999.

RANGEL-BETTI, I. C. A. Esporte na escola: mas é só isso professor? Motriz. Rio Claro, v. 1, n. 01, p. 25-31, junho, 1995. Disponível em:

http://www.periodicos.rc.biblioteca.unesp.br/index. php/motriz/article/view/959/889. Acesso em: 10 jan. 2008.

ROSÁRIO, L. F. R. A Educação Física na Escola e suas interfaces com os conteúdos de
História e Ciências nos livros didáticos.

Dissertação (Mestrado em Ciências da

Motricidade) - Departamento de Educação Física, Universidade Estadual Paulista, Rio Claro, 2006.

ROSÁRIO, L. F. R.; DARIDO, S. C. A Sistematização dos Conteúdos da Educação Física na Escola: a perspectiva dos professores experientes. Motriz. Rio Claro, v. 11, n. 03, p. 167-178, set./dez., 2005. Disponível em: http://www.periodicos.rc.biblioteca.unesp.br/index. php/motriz/article/view/78/58. Acesso em 25 de janeiro de 2009.

SILVA, E. L.; MENEZES, E. M. Metodologia de pesquisa e elaboração de dissertação. 3 . ed. rev. atual. Florianópolis: Laboratório de Ensino a Distância, 2001.

ZABALA, A. A prática educativa: como ensinar. Porto Alegre: Artmed, 1998.

Esse artigo foi apresentado em Sessão Temática no VI Congresso Internacional de Educação Física e Motricidade Humana e XII Simpósio Paulista de Educação Física, realizado pelo Departamento de Educação Física do IB/UNESP Rio Claro, SP de 30/4 a 03/5 de 2009.

Endereço:

Osmar Moreira de Souza Júnior

Av. 6, no 1408 - Cidade Claret

Rio Claro SP Brasil

13503-220

Telefone: (19) 3533.3396 (19) 9677.1581

e-mail: osmar@ufscar.br

Recebido em: 10 de fevereiro de 2009.

Aceito em: 03 de abril de 2009.

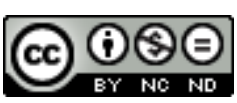

Motriz. Revista de Educação Física. UNESP, Rio Claro, SP, Brasil - elSSN: 1980-6574 - está licenciada sob Licenca Creative Commons 